\title{
Política migratoria y capacidad estatal: la Dirección Nacional de Migraciones (República Argentina) entre los años 2004 y 2015
}

\author{
María Dolores Linares \\ CONICET - Instituto de Estudios Socio-Históricos (UNLPam). La Pampa, Argentina. \\ Email:linares.dolores@gmail.com
}

\begin{abstract}
Resumen:Teniendo en cuenta los cambios en la política pública migratoria de la República Argentina a partir de la sanción de la Ley de Migraciones N²5.871 del año 2004, nos proponemos identificar las acciones llevadas a cabo en la Dirección Nacional de Migraciones en tanto organismo descentralizado del Estado que detenta la autoridad migratoria en todo el territorio argentino, a fin de adecuarse institucionalmente a la nueva ley, para examinar su contribución a la capacidad estatal en esta cuestión. Se realizó para ello un análisis de contenidos mediante la revisión de la bibliografía especializada y de la normativa y un abordaje cualitativo a partir de entrevistas a funcionarios y empleados de la DNM de distintas delegaciones para indicar la capacidad estatal de este organismo en un período de cambio institucional entre los años 2004 y 2015.
\end{abstract}

Palabras claves:Instituciones, política pública, capacidad estatal, Argentina

\section{Immigration policy, institutions and State capacity: the National Migration Office of Argentina (Dirección Nacional de Migraciones) between 2004 and 2015}

\begin{abstract}
Considering the recent changes in Argentina's migration policy since the enactment of the Migration Law $N^{\circ} 25.871$ of 2004, we intend to identify the actions that the Dirección Nacional de Migraciones (DNM) -as a decentralized State agency that holds the migration authority throughout the Argentine territorycarried out in order to adapt institutionally to the new law and to examine its contribution to the State capacity on this issue. We analyzed the content of specialized bibliography and legislation and tried a qualitative approach through interviews with employees of the DNM from different parts of the country to indicate the state capacity of this agency in a period of institutional change between 2004 and 2015.
\end{abstract}

Keywords: Institutions, public policy, state capacity, Argentina

\section{Política migratória e capacidade estatal: a Dirección} Nacional de Migraciones (Argentina) entre os anos 2004 e 2015

Resumo: Tendo em vista as mudanças na política pública migratória da República Argentina a partir da sanção da Lei de Migrações NO 25.871 do ano 
2004, propomos identificar as ações levadas a cabo na Dirección Nacional de Migraciones em tanto organismo descentralizado do Estado que tem a autoridade migratória em todo o território argentino, a fim de adequar-se institucionalmente à nova lei, para examinar sua contribuição à capacidade estatal nesta questão. Realizouse para isso uma análise de conteúdos mediante a revisão da bibliografia especializada e das normas e uma abordagem qualitativa a partir de entrevistas a empregados da DNM de diferentes delegações para indicar a capacidade estatal deste organismo num período de mudança institucional entre os anos 2004 e 2015.

Palavras-chave: Instituições, política pública, capacidade estatal, Argentina

\section{Introducción}

Las migraciones internacionales están reguladas por políticas públicas que responden a diferentes modelos de sociedad ideológicamente configurados (Novick, 2008) y que nospermiten considerar el papel que cumplen las instituciones del Estado en la promoción, restricción y control de la movilidad internacional de personas en cada jurisdicción. En la República Argentina la Ley de Migraciones N²5.871 de diciembre del 2003 (publicada en el Boletín Oficial en enero del 2004)significó, según algunos investigadores y actores sociales ${ }^{1}$, un giro -aunque con matices- en la política pública migratoria al incorporar un enfoque regionalista basado en los derechos de los migrantes. Se planteóasimismo un desafío desde el punto de vista de la burocracia estatal: que las instituciones encargadas de la cuestión migratoria se adecuaran para poder cumplir con su función en tanto dispositivos de gestión. La disrupción por el cambio en la filosofía del dispositivo normativo evidenció que el organismo del Estado encargado de dicha cuestión en Argentina, la Dirección Nacional de Migraciones (en adelante DNM), no podía cumplir su función sin una modificación sustantiva en su estructura, en sus objetivos y en su cultura organizacional. De hecho, como veremos más adelante, un Decreto del Poder Ejecutivo Nacional (en adelante PEN) declaró a este organismo en “emergencia administrativa”. En esteartículo nos proponemos entonces identificar las acciones llevadas a cabo en la DNM en tanto organismo descentralizado del Estado que detenta la autoridad migratoria en todo el territorioargentino,a fin de adecuarse institucionalmente a la Ley $\mathrm{N}^{\circ}$ 25.871,para examinar su contribución a la capacidad estatal en esta cuestión.

Partimos de la perspectiva de la sociología política a través de los aportes deOszlak y O’Donnell (2007 [1978]), O’Donnelly Wolfson(1993), Skocpol (1995), Evans (2007), Isuani (2012), Acuña y Chudnovsky (2013) y Bertranou (2013) para comprender de qué manera la direccionalidad de las políticas públicas y los actores e instituciones que participan en ellas pueden intervenir en la capacidad estatal sobre una cuestión. Tomamos el concepto -algo amplio- de Evans (2007) quien entiende a las instituciones en tanto "reglas del juego" definidas históricamente y construidas socialmente. Acuña y Chudnovsky(2013) agregan que este “conjunto de reglas” puede ser formal e informal) y que están destinados a resolver problemas de 
coordinación y conflictos distribuidos en una sociedad. Este recorte implica tener en cuenta que las instituciones, especialmente las estatales, distribuyen poder y recursos y que son, a su vez, producto de la lucha y negociación de actores desiguales y que operan, además, en contextos donde existen otras instituciones y otras variables sociales que pueden afectar su funcionamiento. Se vislumbra así un problema recurrente para los enfoques institucionalistas: la cristalización de los cambios al interior de las instituciones. Cuando nos referimos a la capacidad estatal, hacemos referencia a la aptitud de los entes estatales para cumplir con los fines requeridos. La aptitud depende, según Bertranou (2013) de tres componentes: las "autorizaciones legales y legitimidad”, la “organización y medios de acción” y el “capital de acción interorganizacional”, que describiremos en el próximo apartado.

En cuanto a la metodología utilizada, se realizó un análisis de contenidos mediante la exhaustiva revisión de la bibliografía especializada y de un cuerpo de leyes, decretos del PEN, decisiones administrativas de la Jefatura de Gabinete de Ministros (en adelante J.G.M.), normativa interna de la DNM (resoluciones y disposiciones) que dan cuenta de una jerarquía diferenciada de normas en cuanto a los entes que las emiten y los años en que entraron en vigencia. Por otro lado, como complemento al análisis documental se procedió con un abordaje cualitativo mediante la realización de entrevistas a cinco (5) funcionarios y ex funcionarios, empleados y ex empleados de la DNM de distintas delegaciones (Sede Central, Delegación La Pampa y Delegación Rosario)² para complejizar el análisis de la capacidad estatal de este organismo. Con el fin de garantizar su anonimato, los entrevistados serán referenciado como DNM No 1 , DNM Nº 2 y así sucesivamente ${ }^{3}$.

Con el fin de organizar nuestra argumentación, comenzamos definiendo los lineamientos conceptuales y metodológicos sobre los cuales se basa nuestro análisis. Posteriormente se repasan los cambios y continuidades más relevantes entre los dos últimos dispositivos normativos de política pública migratoria argentina: la Ley N²2.439 de 1981 y la Ley 25.871 de 2004. En ese apartado se describen asimismo los actores que intervinieron en el debate y sanción de dichos dispositivos normativos. En tercer lugar,se describe la Dirección Nacional de Migraciones en tanto instrumento de gestión y en un cuarto apartado se examinanlos objetivos y las acciones llevadas a cabo por el organismo entre 2004 y 2015 tendientes a adecuarse a la nueva normativa. El quinto apartado analiza dichos objetivos y acciones en función de la construcción de capacidad estatal y el último apartado las pone en cuestión a partir de las voces de los agentes estatales entrevistados. En la conclusión, se retoman las ideas principales y se proponenciertas líneas para profundizar el tema de investigación.

\section{Capacidad estatal, políticas públicas y actores: un Estado bajo la lupa}

Para analizar la capacidad estatal de una institución nos valemos de un esquema conceptual algo esquemático que parte de la idea de la 
existencia de un Estado que, mediante las unidades que lo componen, tiene la facultad de fijarse objetivos autónomos realizables mediante sus políticas públicas (Skocpol, 1995). Las políticas públicas son, según Oszlak y O’Donnell (2007 [1978]), un conjunto de acciones y omisiones que manifiestan una modalidad de intervención del Estado en relación con una cuestión que concilia el interés de otros actores de la sociedad civil. Los actores son "todo sujeto individual o colectivo cuya identidad les permite reconocerse como colectividad o como parte de ella y con capacidades estratégicas" (Acuña y Chudnovsky, 2013, p. 36). Dentro y fuera de las instituciones, los actores tienen la posibilidad de identificar sus intereses e ideología, traducirlos en objetivos y diseñar acciones para alcanzarlos.

Para comprender cómo se ejecuta una política pública, Isuani (2012) propone el concepto de Instrumentos de Políticas Públicas (IPP) en tanto materializadores de la intervención estatal para solucionar las cuestiones de la agenda política. El autor reconoce tres tipos de instrumentos: 1) un dispositivo normativo, compuesto por leyes, decretos y reglamentos que encuadran y autorizan una política pública (poder legislativo y ejecutivo del estado); 2) un dispositivo de gestión que supone la estructuración de un esquema organizacional para llevar adelante acciones de gestión operativa y de control, y 3) recursos básicos, que pueden ser financieros (endógenos o exógenos), tecnológicos (conocimiento utilizable a escala social para transformar elementos materiales y simbólicos en bienes y servicios) y de recursos humanos (burocracia) (Isuani, 2012).

Las políticas públicas migratorias, que forman parte de la política de población ${ }^{4}$, serían las propuestas y metas elaboradas desde el aparato estatal con el fin específico de influir en el tamaño, la composición, el origen, la dirección, el asentamiento y la integración de los flujos migratorios espontáneos o pertenecientes al proceso global de planificación económico-social (Mármora, 1988, citado en Nejamkis, 2016). En este sentido, entendemos que la capacidad estatal no es abordable en abstracto sino con respecto a las funciones que deben ser cumplidas, a los objetivos específicos propuestos por cada institución.

La definición de capacidad estatal que adelantamos en la introducción de este artículo corresponde a Bertranou (2013) y se refiere a la aptitud de los entes estatales para cumplir con los fines requeridos, es decir, como una condición previa para el logro de resultados. Esta aptitud se desprende, según el autor, de los tres componentes de la capacidad estatal: las "autorizaciones legales y legitimidad”, la "organización y medios de acción” y el “capital de acción interorganizacional”. El primero de estos componentes indica el grado de autorización legal que posee el organismo estatal para llevar a cabo sus acciones, generalmente conferida por un dispositivo normativo, y si los actores sociales y políticos le han otorgado legitimidad institucional para llevar adelante esas acciones. La organización y los medios de acción comprenden las 
dotaciones, atributos y posibilidades de la organización, es decir, los recursos humanos, tecnológicos y materiales, la infraestructura y equipamiento, la estructura organizacional y los recursos financieros. Por último, el capital de acción interorganizacional hace referencia al capital social del organismo en tanto red de relaciones con otros entes estatales y no gubernamentales que puede operar en varios niveles: nacionales, provinciales y locales.

Ahora bien, con respecto a las discusiones en torno al complejo concepto de Estado y teniendo en cuenta la estrategia metodológica para abordar una institución estatal, tenemos presente la advertencia de Renoldi (2015) sobre los riesgos de apoyarnos en una visión normativa del Estado que nos lleve a "pensar desde el Estado" o a realizar un “reduccionismo institucionalista” (Espinoza Molina, 2015). Entendemos al Estado siguiendo a O’Donnelly Wolfson(1993) quienes, aún con una marcada impronta weberiana, lo describen como una entidad que va más allá que el aparato estatal o el conjunto de las burocracias públicas. Para el autor, el Estado es un conjunto de relaciones sociales que establece un orden social en un territorio determinado, respaldando dicho orden con una garantía coercitiva centralizada (O’Donnell y Wolfson, 1993, p. 165). Esta perspectiva, aunque se presente como "Estado-céntrica”, no pretende sin embargo atribuirle al Estado nacional un poder impersonal, legal y normalizador que, mediante sus prácticas, llegue de manera unívoca a todo el ámbito de lo social. Por esta razón, presentaremos algunos extractos de las entrevistas realizadas para dar cuenta, a manera de ejemplo, de cómo la pretendida “impersonalidad” del Estado estaría presente o no en la agencia de los cuadros políticos y administrativos de la DNM. Esto equivaldría a apelar desde otra óptica a la dinámica organizacional de la DNM, corriéndonos del lugar de abordaje para observar el "Estado desde adentro", como indican Bohoslavsky y Soprano (2010). Entre la premisa de "no personalizar al Estado" como un ente indivisible y con vida propia (Bohoslavsky y Soprano, 2010) y la de “personalizar al Estado” definiendo “quién y quiénes son el Estado en cada momento determinado”, intentaremos entonces advertir asimismo la manera en la que el Estado se piensa y se construye a sí mismo a través de sus agentes y de sus acciones ${ }^{5}$.

\section{Cambios en los dispositivos normativos y los actores de la política pública: De la Ley 22.439 (1981) a la Ley 25.871 (2004)}

La cuestiónde las migraciones internacionales ha sido central en las políticas de desarrollo de la República Argentina, según indican investigadores como Susana Novick (2008, 2012) y Eduardo Domenech (2009), entre otros, y se han cristalizado a través de los dispositivos normativos.La primera ley general sobre la cuestión migratoria fue la Ley Nº 817 de Inmigración y Colonización de 1876 y la segunda fue la N²2.439 del PEN, Ley 
General de Migraciones y de Fomento de la Inmigración (conocida como Ley Videla), sancionada durante la última dictadura militar argentina en 1981.Para sintetizar, entre la Ley Videla de 1981 y la Ley de Migraciones 25.871 del año 2004, encontramos tres diferencias fundamentales: unarelacionada a laorientación del dispositivo (de carácter ideológico, según Bertranou, 2013), otra de carácter formal basada en el modo de formulación de las normas y una últimarespecto los actores que intervinieron en su formulación.

La orientaciónde la Ley Videla fue principalmente restrictiva y prevaleció una óptica de seguridad policial en la regulación de la política migratoria. La ley estableció la ilegalidad por ingreso o por permanencia (Pacecca, 2000), dejando a los migrantes indocumentados sujetos a la detención y expulsión por acción directa de la DNM y sin posibilidad de representación legal ante la justicia. Se habilitó a la DNM a realizar inspecciones y allanamientos sin orden judicial en domicilios (Pacecca, 2000; Novick, 2008), se impusieron restricciones al trabajo por requisitos de contratación muy difíciles de cumplir y se impidió a los inmigrantes indocumentados el acceso a los servicios de salud, educación y justicia, obligando a los funcionarios responsables en cada ámbito a denunciar la situación ante las autoridades (Courtis y Pacecca, 2008, Novick, 2008) ${ }^{6}$. Durante los gobiernos democráticos de Raúl Alfonsín (1983-1989), Carlos Menem (1989-1999) y Fernando De La Rúa (1999-2001) se adoptaron posturas ambiguas: por un lado,se aplicaron regímenes de excepción decretados por el PEN bajo la formas de indultos (llamados generalmente “amnistías”) en 1984 y 1992 (Sassone, 2004) y se firmaron convenios bilaterales con países limítrofes. Por otro lado, se autorizaron disposiciones de la DNM de carácter restrictivo y se reglamentó la Ley Videla en tres oportunidades, aunque desde la Reforma Constitucional de 1994 muchos de sus artículos habían pasado a ser anticonstitucionales. En este sentido, la Ley de Migraciones $N^{\circ} 25.871$ del año 2004 incorporó dos ejes que estaban ausentes en la normativa anterior: la perspectiva de los derechos humanos y el enfoque migratorio regionalista (Le Gall y Sassone, 2008) al aplicar el criterio de nacionalidad para la residencia temporaria (Art. 23) que beneficia a los ciudadanos del Mercosur y asociados. Esta ley tiene un espíritu inclusivo, reconoce a la migración como un derecho humano fundamental que el Estado debe garantizar y favorece la regularización de los migrantes provenientes de países limítrofes o mercosureanos. Además, determina que los migrantes tienen derecho al acceso libre e irrestricto a los servicios de salud, justicia y educación, sin perjuicio de su condición migratoria. El migrante indocumentado no es considerado ilegal sino "irregular", no pudiendo ser detenido sino "retenido" y con derecho al acceso a la Justicia. Que esta ley sea inclusiva no quiere decir que sea irrestricta o masiva: sigue un modelo de integración de los migrantes de característicasasimilacionista (Domenech, 2009) y no reconoce los derechos políticos, una deuda que algunos investigadores y actores sociales (Penchaszadeh, 2012; CELSFIDH, 2011) consideran como el talón de Aquiles de esta "nueva normativa" (se trata de un millón de personas que no tienen derecho a elegir a 
sus representantes). Tal como advierte Domenech (2013), esta “nueva política migratoria” argentina se podría enmarcar dentro de la perspectiva de la gobernabilidad migratoria que, si bien abandona las medidas restrictivas y excluyentes, no pierde de vista las nociones de control y de seguridad para conducir, canalizar y regularizar los flujos migratorios hacia el país, como veremos en el siguiente apartado.

Sobre el aspecto formal que atañe a la formulación de estos últimos dos dispositivos normativos es remarcable que, antes de la Ley de Migraciones N² 25.871 (2004), la última ley sobre la “cuestión” migratoria con trámite parlamentario regular fue la Ley de Defensa Nacional $\mathrm{N}^{\circ}$ 7902 de 1910 (Рacecca, 2000). Durante esos 96 años el Poder Ejecutivo Nacional, mediante sus decretos, fue la unidad del Estado que detentó el monopolio de la normativa migratoria (Courtis, 2006). Además, se le fueron otorgando funciones de poder de policía a las unidades de gestión del Estado, en especial a la DNM (Pacecca, 2000; Courtis y Pacecca, 2008). Desde la década del 90 se presentaron numerosos proyectos de ley para reemplazar la Ley Videla y el proyecto de ley presentado por el Diputado socialista Rubén Giustiniani en el año 2003 -quien ya lo había presentado sin éxito en el año 2001- fue resultado de arduos debates parlamentarios antes de sancionarse como Ley 25.871. Contó con el apoyo del gobierno peronista de Néstor Kirchner (2003-2007) y tuvo una buena recepción en ambas cámaras legislativas, habiendo sido tratado en la Comisión de Población y Recursos Humanos de la Cámara de Diputados y en la Comisión de Población y Desarrollo de la Cámara de Senadores. Sin embargo, su sanción no hubiese sido posible sin el trabajo de numerosas instituciones sociales vinculadas a la cuestión migratoria: la agenda de esta cuestión estuvo marcada por la lucha que llevaron a cabo, durante la década del 90, instituciones religiosas, organizaciones no gubernamentales de derechos humanos, investigadores y asociaciones de migrantes organizados (Badaró, 2006).

Llegamos así a identificar otros actores interesados en la formulación de la política pública migratoria. El actor público por excelencia es la DNM, en tanto “autoridad de aplicación” de la Ley 25.871 según su Art. 105. Algunos actores privados pudieron intervenir en la formulación del proyecto de ley, así como en la posterior reglamentación, cuando el Estado, a través de la DNM, buscó crear consenso en el año 2008 a partir de organizaciones de la sociedad civil e incentivó la creación de una Comisión Asesora en la materia, compuesta por la Organización Internacional para las Migraciones (OIM), el Alto Comisionado de las Naciones Unidas para los Refugiados (ACNUR), la Fundación Comisión Católica Argentina de Migraciones (FCCAM), el Centro de Estudios Migratorios Latinoamericanos (CEMLA), el Centro de Estudios Legales y Sociales (en adelante CELS) y la Asamblea Permanente por los Derechos Humanos (APDH).

En medio de estos actores institucionalizados, se encuentran los migrantes, organizados a veces como agentes (en organizaciones cultu- 
rales, políticas, religiosas, deportivas) y otras veces desorganizados pero poseedores de intereses claros, como por ejemplo la regularización migratoria, la reunificación familiar, etcétera. Los grupos de migrantes participaron activamente en los debates parlamentarios pero sólo a través de las organizaciones de DDHH y religiosas o académicas que contaban con mayor visibilidad y legitimidad.

\section{Dispositivo de Gestión: la Dirección Nacional de Migraciones como autoridad migratoria}

La Dirección Nacional de Migracionesfue creada en 1949 y es un organismo descentralizado dependiente del Ministerio del Interior y de Transporte (que desde 2016 se denomina Ministerio del Interior, Obras Públicas y Vivienda). Pese a existir otros organismos estatales que atienden cuestiones relacionadas con los migrantes, la DNM es el organismo encargado de aplicar la política migratoria en toda la República Argentina. Tiene una estructura organizativa territorial para atender las demandas y los requerimientos de cada región del país (Sassone, 2004), dividiéndose en una Sede Central y un Centro de Documentación Rápida en la Ciudad Autónoma de Buenos Aires, 29 Delegaciones en todo el país, seis Oficinas Migratorias y cuatro unidades móviles de documentación y trámites. La función, misión, visión y prioridades de la DNMestán determinadas por la Ley $\mathrm{N}^{\circ} 25.871$ y su Decreto Reglamentario 616 del año 2010. Según el Art. 107 de la Ley 25.871, la DNM tiene la “competencia” (capacidad, aptitud, así como jurisdicción) para entender en la admisión y otorgamiento de residencias; establecer nuevas delegaciones; conceder permisos de ingresos, prórrogas de permanencia y cambios de calificación para extranjeros; controlar el ingreso y egreso de personas al país y ejercer el control de permanencia y el "poder de policía de extranjeros en todo el Territorio de la República”.Además tiene como función la promoción de la regularización documentaria de inmigrantes y la intervención cuando se infringe la ley de migraciones. Es importante notar que este artículo no contiene cambios sustanciales con respecto a la normativa anterior (Ley 22.439 de 1981).

Como indica Nejamkis (2012), la DNM es una unidad compleja de abordar, no sólo por su amplia estructura burocrática extendida por todo el país sino porque se trató, durante décadas, de un organismo que actuó prácticamente de manera autónoma a los gobiernos democráticos (respondiendo a normativas decretadas) y que entendió la cuestión migratoria en términos de seguridad o policíacos. Eso último se debe a que, durante muchos años (hasta la creación del Ministerio de Seguridad en 2010), las fuerzas de seguridad nacionales también estaban bajo la órbita del Ministerio del Interior y, en la práctica, la DNM funcionaba como una policía migratoria. Por esta razón, algunos de nuestros entrevistados caracterizaron a la DNM como un organismo "oscuro", de ambiente "difícil” o “cerrado". 
Recordando que nuestro objetivo en este artículo es el de identificar las acciones llevadas a cabo en la DNM para adecuarse institucionalmente a la Ley $\mathrm{N}^{\circ} 25.871$, que contribuyan a la capacidad estatal en la cuestión migratoria, remarcamos que este tipo de funcionamiento tuvo que ser revisado a partir del año 2004. Durante el período 2003-2015 la DNM contó con tres Directores Nacionales. Al momento de asumir la Presidencia de la Nación Néstor Kirchner (2003-2007) el Director era Jorge Rampoldi y en septiembre de 2003 ocupó la dirección el abogado Ricardo Rodríguez hasta el año 2007, cuando fue removido por la presidenta (Cristina Fernández de Kirchner (2007-2011 y 2011-2015), quien nombró en su reemplazo a Martín Arias Duval (2007- 2015).

Con respecto a su estructura interna y funcionamiento, aún en el año 2004 la DNM contaba con una estructura organizativa que databa del año 1996 (Decreto del PEN 1659/96) acorde al espíritu y necesidades de la normativa anterior. Además, hasta la Reglamentación de la Ley 25.871 en el año 2010 la DNM utilizó para su funcionamiento interno el Reglamento de Migración de 1965del Decreto PEN 4418/65 (CELS, 1999). Por dicha razón y teniendo en cuenta estos desajustes, en el mes de julio de 2004, el Decreto 836 del PEN declaró la emergencia administrativa de la DNM debido a que -entre otros motivos como la detección de redes delictuales dedicadas al tráfico de personas- el organismo presentaba "severas irregularidades operativas" así como fallas en la estructura organizativa y en la dotación del personal. El decreto anunciaba que se había realizado una evaluación de la situación en que se encontraban las distintas áreas de la DNM (según la estructura organizacional de 1996) y se habían detectado los principales problemas de cada una, que tenían que ver con: a) la ausencia de mecanismos acordes a la dinámica de la gestión; b) deficiencias edilicias y de infraestructura; c) existencia de una "normativa migratoria antigua totalitaria"; d) inadecuada estructura organizacional; e) falta de información y asesoramiento a migrantes y f) el desconocimiento de la política migratoria Argentina en el mundo ${ }^{7}$.

El cambio de la estructura organizacional llegó recién en los años 2008 y 2012 mediante dos Decisiones Administrativas de la Jefatura de Gabinete de Ministros (J.G.M). En estas re-estructuraciones se sumaron tres Direcciones y dos Departamentos del Primer Nivel Operativo, como se muestra en el Cuadro 1. 


\section{Cuadro1: Estructuras organizativas Primer Nivel Operativo de la DMN, años 1996, 2008 y 2012.}

\begin{tabular}{|c|c|c|c|}
\hline $\begin{array}{l}\text { Organismo: Dirección } \\
\text { Nacional de } \\
\text { Migraciones }\end{array}$ & $\begin{array}{c}1996 \\
\text { Decreto } 1659 / 96 \text { del } \\
\text { PEN Apruébase la } \\
\text { estructura } \\
\text { organizativa DNM }\end{array}$ & $\begin{array}{c}2008 \\
\text { Decisión Administrativa } \\
250 / 2008 \text { de la Jefatura de } \\
\text { Gabinete de Ministros. } \\
\text { DNM, Estructura } \\
\text { organizativa }\end{array}$ & $\begin{array}{c}2012 \\
\text { Decisión Administrativa } \\
\text { 1395/2012de la Jefatura de } \\
\text { Gabinete de Ministros. } \\
\text { Estructura organizativa del } \\
\text { primer nivel operativo. }\end{array}$ \\
\hline Dependencia & $\begin{array}{c}\text { Subsecretaria de } \\
\text { Población del } \\
\text { Ministerio del Interior }\end{array}$ & Ministerio del Interior & $\begin{array}{l}\text { Ministerio del Interior y } \\
\text { Transporte }\end{array}$ \\
\hline \multirow[t]{6}{*}{$\begin{array}{c}\text { Primer Nivel } \\
\text { Operativo } \\
\text { (Responsabilidad } \\
\text { primaria) }\end{array}$} & $\begin{array}{c}\text { Dir. Gral. de } \\
\text { Administración y } \\
\text { Recursos Humanos } \\
\text { (Gestión de recursos } \\
\text { financieros, humanos y } \\
\text { materiales) }\end{array}$ & $\begin{array}{c}\text { Dir. Gral. de } \\
\text { Administración } \\
\text { (Administración y } \\
\text { capacitación de los recursos } \\
\text { humanos) }\end{array}$ & $\begin{array}{l}\text { Dir. Gral. de Administración } \\
\text { (Administración y capacitación de } \\
\text { los recursos humanos) }\end{array}$ \\
\hline & $\begin{array}{l}\text { Dir. de Admisión de } \\
\text { Extranjeros } \\
\text { (Fiscalizar la admisión } \\
\text { de los extranjeros) }\end{array}$ & $\begin{array}{l}\text { Dir. Gral. de Inmigración } \\
\text { (Instrumentar y supervisar la } \\
\text { admisión de los extranjeros) }\end{array}$ & $\begin{array}{l}\text { Dir. Gral. de Inmigración } \\
\text { (Instrumentar y supervisar la } \\
\text { admisión de los extranjeros) }\end{array}$ \\
\hline & $\begin{array}{l}\text { Dir. de Control } \\
\text { Migratorio } \\
\text { (Control ingreso y } \\
\text { egreso y permanencia } \\
\text { de extranjeros. } \\
\text { Coordinar y fiscalizar } \\
\text { las Delegaciones) }\end{array}$ & $\begin{array}{l}\text { Dir. Gral. de Movimiento } \\
\text { Migratorio } \\
\text { (Dirigir el control migratorio } \\
\text { relativo al ingreso y egreso) }\end{array}$ & $\begin{array}{l}\text { Dir. Gral. de Movimiento } \\
\text { Migratorio } \\
\text { (Dirigir el control migratorio } \\
\text { relativo al ingreso y egreso) }\end{array}$ \\
\hline & $\begin{array}{l}\text { Dir. de Asuntos } \\
\text { Jurídicos } \\
\text { (Asesorar legalmente } \\
\text { en asuntos de } \\
\text { competencia DNM) }\end{array}$ & $\begin{array}{l}\text { Dir. Gral. Técnica-Jurídica } \\
\text { (Legislación general e } \\
\text { instrumentación normativa } \\
\text { de las políticas pública. } \\
\text { Patrocinio legal) }\end{array}$ & $\begin{array}{l}\text { Dir. Gral. Técnica-Jurídica } \\
\text { (Legislación general e } \\
\text { instrumentación normativa de las } \\
\text { políticas pública. Patrocinio legal) }\end{array}$ \\
\hline & $\begin{array}{l}\text { Dir. de Sistemas } \\
\text { (Diseñar, seguir, } \\
\text { evaluar, implementar } \\
\text { los sistemas de } \\
\text { información) }\end{array}$ & $\begin{array}{l}\text { Dir. de Sistemas } \\
\text { (Implementación y } \\
\text { seguimiento de las politicas } \\
\text { relativas a las Tecnologias } \\
\text { de la información y las } \\
\text { Comunicaciones) }\end{array}$ & $\begin{array}{l}\text { Dir. de Sistemas y Tecnologías } \\
\text { de la Información } \\
\text { (Implementación de politicas } \\
\text { sobre Tecnologías de la } \\
\text { Información y Comunicaciones. } \\
\text { Equipamiento y software) }\end{array}$ \\
\hline & $\begin{array}{l}\text { Depto. de Sumarios } \\
\text { (Dirigir la instrucción } \\
\text { de los sumarios } \\
\text { administrativos) }\end{array}$ & $\begin{array}{c}\text { Depto. de Sumarios } \\
\text { (Sin Responsabilidad } \\
\text { primaria, sólo "Acciones") }\end{array}$ & $\begin{array}{l}\text { Depto. de Sumarios } \\
\text { (Aplicación del Reglamento de } \\
\text { Investigaciones Administrativas, } \\
\text { determinar la existencia o no de } \\
\text { responsabilidad disciplinaria) }\end{array}$ \\
\hline \multirow[t]{3}{*}{ Agregados en 2008} & & $\begin{array}{c}\text { Depto. de Prensa } \\
\text { (Sin Responsabilidad } \\
\text { primaria, sólo "Acciones") }\end{array}$ & $\begin{array}{c}\text { Depto. de Prensa } \\
\text { (Relaciones con la prensa, } \\
\text { difusión interna y extema) }\end{array}$ \\
\hline & & $\begin{array}{c}\text { Dir. de Delegaciones } \\
\text { (Coordinación de politicas, } \\
\text { programas y acciones en las } \\
\text { Delegaciones) }\end{array}$ & $\begin{array}{c}\text { Dir. de Delegaciones } \\
\text { (Coordinación de politicas, } \\
\text { programas y acciones en las } \\
\text { Delegaciones del interior del pais) }\end{array}$ \\
\hline & & $\begin{array}{c}\text { Dir. de Asuntos } \\
\text { Internacionales y Sociales } \\
\text { (Aplicación de la política } \\
\text { internacional establecida por } \\
\text { el Estado) }\end{array}$ & $\begin{array}{l}\text { Dir. de Asuntos Internacionales } \\
\text { y Sociales } \\
\text { (Aplicación de la politica } \\
\text { intemacional establecida por el } \\
\text { Estado) }\end{array}$ \\
\hline \multirow[t]{2}{*}{ Agregados en 2012} & & & $\begin{array}{l}\text { Dir. de Información Migratoria } \\
\text { (Recopilación, procesamiento, } \\
\text { análisis, producción estadistica y } \\
\text { comunicación interma, } \\
\text { formulación de políticas de } \\
\text { gestión (art. } 3^{\circ} \text { Ley } \mathrm{N}^{\circ} 25.871 \text { )) }\end{array}$ \\
\hline & & & $\begin{array}{l}\text { Depto. de Gestión de Calidad } \\
\text { (Desarrollo de politicas de } \\
\text { modemización del estado, } \\
\text { implementación de programas de } \\
\text { mejoramiento de la calidad del } \\
\text { servicio) }\end{array}$ \\
\hline $\begin{array}{c}\text { Dotación Global de } \\
\text { Personal } \\
\text { De los cuales: }\end{array}$ & $\begin{array}{c}653 \\
394 \text { Permanentes } \\
257 \text { Temporarios } \\
2 \text { Directivos (Director } \\
\text { Nacional y Auditor } \\
\text { Intemo Titular) }\end{array}$ & $\begin{array}{c}1708 \\
1670 \text { Permanentes } \\
\text { 35 Temporarios } \\
\text { 3 Directivos (Director } \\
\text { Nacional, Subdirector } \\
\text { Nacional y Auditor Interno } \\
\text { Titular) }\end{array}$ & $\begin{array}{c}\text { 2084 } \\
\text { 2046 Permanentes } \\
\text { 35 Temporarios } \\
\text { 3 Directivos (Director Nacional, } \\
\text { Subdirector Nacional y Auditor } \\
\text { Interno Titular) }\end{array}$ \\
\hline
\end{tabular}

Fuente: Elaboración propia sobre la base del Decreto 1659/96 del P E.N., la Decisión Administrativa 250/2008, J.G.M. y la Decisión Administrativa 1395/2012, J.G.M. 
En el próximo apartadodistinguiremos los principales ejes sobre los cuales giraron los objetivos y las acciones de la DNM en estos añospara adecuarse al cambio normativo dentro de la política migratoria argentina.

\section{Cambios en la DNM entre los años 2004-2015: emergencias, objetivos y acciones}

Los cambios realizados en la estructura organizacional de la DNM respondieron, según el Decreto 836/2004, a que la Argentina estaba "redefiniendo su política migratoria” a partir de ciertos objetivos y que esa situación requería acciones concretas para lograr los resultados esperados. Una de las acciones, tal vez la más urgente, fue el lanzamiento del Programa Nacional de Normalización Documentaria Migratoria conocido como "Patria Grande”, anunciado en el mismo Decreto.Luego, el conjunto de los objetivos y acciones que se dio el Estado a través de la DNM fueron descriptos en los Informes y Memorias Institucionales de Gestión, que figuran en la página web del organismo divididos en dos tipos: un Informe de Control Interno y Gestión (ICIG) que abarca el período junio del 2003 hasta junio del 2007 y que corresponde a la dirección Rodríguez y ocho (8) Memorias Institucionales de Gestión para cada año entre 2008 y 2015 que corresponden a la administración de AriasDuval.

El Informe de Control Interno y Gestión (ICIG) (2003-2007) planteó como objetivos procurar un marco normativo para la regularización de todos los inmigrantes "a fin de permitir su inserción legal y social” y asegurar los controles sobre las personas en el ingreso y egreso al país. En las Memorias Institucionales de Gestión (MIG) se agregaron los siguientes objetivos: "intensificar la política migratoria inclusiva"; "afianzar la seguridad en las fronteras y la soberanía”; "diseñar y aplicar programas para la mejor gestión de funciones y servicios”; reglamentar Ley 25.871; mejorar la imagen institucional web; lograr mayor federalismo a través de reuniones de delegaciones y "gestionar una nueva estructura organizacional". En el año 2011 se redacta un objetivo general que sintetizaría la nueva orientación de la gestión:
"Ser un organismo ágil, moderno, eficiente y transparente. Compro- metido con la plena integración de las personas y el respeto a los derechos humanos del migrante. Generador de información útil para la toma de decisiones en materia demográfica o poblacional, y para la cooperación inter-jurisdiccional e internacional” (MIG, 2011).

Además, en ese año se explicita como objetivo profundizar los vínculos con las colectividades y entre los años 2012 y 2015 se procura la constitución de un ámbito académico para contribuir a perfeccionar el conocimiento, actitudes y habilidades de los agentes gubernamentales, no gubernamentales y la sociedad civil en general, vinculados al ámbito migratorio y de refugiados. Otros objetivos perseguidos entre 2012 y 2015 fue- 
ron: implementar la firma digital del personal (“despapelización” de la DNM); proseguir con las innovaciones tecnológicas y el equipamiento en los procesos relacionados con trámites de residencia y control migratorio en todo el país y mantener y acrecentar los compromisos de calidad asumidos en la Cuarta Carta Compromiso con el Ciudadano y en las Normas ISO 9001:2008.

En cuando a las acciones realizadas tendientes a cumplir con los objetivos requeridos por la DNM, hemos sistematizado la información a partir de cuatro ejes (legislación; cambios organizacionales; apertura institucional y convenios varios; controles de permanencia y fronterizos) sintetizados en el Cuadro 2:

\section{Cuadro 2 \\ Principales acciones institucionales de la DNM (2008-2015)}

\begin{tabular}{|c|c|c|}
\hline $\begin{array}{l}\text { Acciones y } \\
\text { Resultados } \\
\text { sobre: }\end{array}$ & $\begin{array}{l}\text { Período 2008-2011 ( } 1^{\circ} \text { Gobierno CFK) } \\
\text { MIGs 2008, 2009, 2010 y } 2011\end{array}$ & $\begin{array}{l}\text { Período } 2012-2015\left(2^{\circ} \text { Gobierno CFK }\right) \\
\text { MIIGs } 2012,2013,2014 \text { y } 2015\end{array}$ \\
\hline Legislación & $\begin{array}{l}\text {-Creación de Comisión Asesora } \\
\text {-Reglamentación de la Ley (Decreto } \\
616 / 2010 \text { ) } \\
\text {-Creación del Manual de Procedimientos } \\
\text { de Control del Movimiento Migratorio } \\
\text {-Conformación de la Comisión Nacional } \\
\text { para los Refugiados (Conare) }\end{array}$ & $\begin{array}{l}\text {-Programa Siria: visado humanitario } \\
\text {-Prórroga y mejoramiento del Programa Siria } \\
\text { (Dis. DNM N }{ }^{\circ} 4099 / 2015 \text { ) } \\
\text {-Programa de regularización para dominicanos y } \\
\text { senegaleses (Dis. DNM } N^{\circ} 1 / 13 \text { y } 2 / 13 \text { ). } \\
\text {-Puesta en marcha del Programa de Abordaje } \\
\text { Territorial }\end{array}$ \\
\hline $\begin{array}{l}\text { Cambios } \\
\text { organizacional } \\
\text { es }\end{array}$ & $\begin{array}{l}\text { Diseño tecnológico del Sistema } \\
\text { informático deAdmisión de Extranjeros } \\
\text { (SADEX) } \\
\text {-Consolidación de la gestión pública: firma } \\
\text { de la Carta Compromiso con el Ciudadano } \\
\text {-Modernización web: nuevas aplicaciones } \\
\text { instrumentales e informativas. } \\
\text {-Posicionamiento DNM: identidad } \\
\text { institucional } \\
\text {-Ampliación y profundización del } \\
\text { federalismo: reuniones de delegados para } \\
\text { reafirmar la politica migratoria, atender las } \\
\text { problemáticas particulares de cada región } \\
\text { y capacitar en normativas, tecnología y } \\
\text { operatividad. } \\
\text {-Restructuración DNM: intensificación del } \\
\text { esquema institucional y funcional } \\
\text {-Formación de los empleados: plataforma } \\
\text { Moodle de capacitación a distancia } \\
\text {-2009: Tumos por call center y vía web } \\
\text {-Mejoramiento escalafonario de } 360 \\
\text { empleados } \\
\text {-Creación del Área Técnica de Análisis } \\
\text { Documental (seguridad) } \\
\text {-Mejoramiento de las infraestructuras } \\
\text { edilicias } \\
\text {-Creación del Departamento de } \\
\text { Extranjeros Judicializados } \\
\text {-2010: Apertura Delegación San Luis, } \\
\text { Alte. Brown y oficinas migratorias en } \\
\text { Puerto Gral. San Martín (Santa Fe) y } \\
\text { Aimogasta (La Rioja) }\end{array}$ & $\begin{array}{l}\text {-Reestructuración del organigrama institucional } \\
\text {-Instrumentación firma y expediente digital en } \\
\text { trámites de radicación, despapelización. } \\
\text {-Creación del Área de Información Migratoria, } \\
\text { luego elevada al rango de Dirección } \\
\text {-Curso Obligatorio de Inducción para el Personal } \\
\text { Ingresante y obligatoriedad de aprobar el Curso } \\
\text { de Documentología } \\
\text {-Organización y diseño de nueve regiones } \\
\text { geográficas para sistematizar los requerimientos } \\
\text { logisticos, de recursos humanos y de control de } \\
\text { gestión, para la totalidad de los pasos de frontera } \\
\text { del país } \\
\text {-Creación de Mesa de Diálogo Migratorio para } \\
\text { analizar y buscar mejorar las políticas públicas } \\
\text {-Mejoramiento y atención de los recursos } \\
\text { humanos para un plantel de más de } 3.800 \\
\text { empleados. } \\
\text {-Distinción a la DNM por parte del Instituto } \\
\text { Nacional de la Administración Pública (INAP) } \\
\text { por los progresos realizados en la la } \\
\text { institucionalización de la planificación de la } \\
\text { capacitación en la Primera Jomada Argentina de } \\
\text { Capacitación en el Estado. } \\
\text {-2014: Creación Departamento de Información, } \\
\text { Asistencia y Cooperación (DIAC) } \\
\text {-Creación Delegación Florencio Varela y Of. } \\
\text { Migratoria CABA Oeste } \\
\text {-Creación Delegación Villa Gesell. }\end{array}$ \\
\hline
\end{tabular}




\begin{tabular}{|c|c|c|}
\hline $\begin{array}{l}\text { Apertura } \\
\text { institucional y } \\
\text { Convenios } \\
\text { varios }\end{array}$ & $\begin{array}{l}\text {-Creación de una campaña gráfica } \\
\text { institucional } \\
\text {-Publicación de dos libros } \\
\text {-Actividades culturales con colectividades } \\
\text {-2011: Organización de la Fiesta de las } \\
\text { Colectividades y del Día del Inmigrante } \\
\text {-Incremento del protagonismo del } \\
\text { organismo en la esfera Internacional: } \\
\text { FEMM, OIM, etc. } \\
\text {-Profundización de los vínculos } \\
\text { institucionales con ministerios, entidades } \\
\text { estatales, áreas de la Justicia, organismos } \\
\text { intermacionales, provincias, gobiemos } \\
\text { extranjeros y ONGs } \\
\text {-Complementación con la Corte Suprema } \\
\text { de Justicia } \\
\text {-Convenio con la Procuración General de } \\
\text { la Nación para que puedan acceder a la } \\
\text { base de datos DNM }\end{array}$ & $\begin{array}{l}\text {-Activa participación con ONGs (migrantes y } \\
\text { sociales), eventos culturales y políticos } \\
\text { - Centros de Acceso a la Justicia (CAJ) } \\
\text { - Trabajos conjuntos con el Plan "Ahr" del } \\
\text { Ministerio de Desarrollo Social para promover } \\
\text { procesos de inclusión social y desarrollo local de } \\
\text { los pueblos más aislados social y } \\
\text { geográficamente. } \\
\text {-Acuerdo entre la DNM, la CGT, la Universidad } \\
\text { de Tres de Febrero, la Organización Internacional } \\
\text { del Trabajo, la OIM y el IPMA para la realización } \\
\text { de talleres sobre migraciones para la capacitación } \\
\text { y sensibilización de los delegados sindicales de la } \\
\text { CGT. } \\
\text {-Colaboración con el gobierno bonaerense para la } \\
\text { confección de un Registro electoral. } \\
\text {-Fundación del Instituto de Politicas Migratorias } \\
\text { Internacionales y Asilo (IPMA) con la } \\
\text { Universidad Nacional de Tres de Febrero. } \\
\text { Convenio con la Universidad Nacional de Lanús. }\end{array}$ \\
\hline $\begin{array}{l}\text { Controles de } \\
\text { permanencia y } \\
\text { fronterizos }\end{array}$ & $\begin{array}{l}\text { - Resolución de cambio de categoría de } \\
10.000 \text { inmigrantes } \\
\text {-Efectivización de expulsiones de } \\
\text { extranjeros judicializados: } 1.100 \text { en este } \\
\text { periodo. } \\
\text {-Aumento operativos de control de } \\
\text { permanencia (1.454 en } 2009,1.915 \text { en } \\
2010 \text { y } 3.109 \text { en } 2011) \\
\text {-Contratación personal para pasos } \\
\text { fronterizos } \\
\text {-Profundización del control en fronteras }\end{array}$ & $\begin{array}{l}\text {-Aumento operativos de control de permanencia } \\
\text { (3034 en 2012, } 4000 \text { en } 2013,3.933 \text { en } 2014 \text { y } \\
4.300 \text { en 2015). } \\
\text {-2013: la DNM asumió la gestión de } 62 \text { pasos } \\
\text { terrestres bajo control de la Gendarmeria } \\
\text { Nacional: } 700 \text { nuevos inspectores incorporados. } \\
\text {-2015: DNM controla directamente el } 98,06 \% \text { de } \\
\text { los tránsitos fronterizos }\end{array}$ \\
\hline
\end{tabular}

Fuente: Elaboración propia sobre la base de las Memorias Institucionales de Gestión 2008, 2009, 2010, 2011, 2012, 2013, 2014 у 2015.

\section{Objetivos cumplidos: examinando la capacidad estatal de la DNM}

Según lo observado en la normativa consultada, las acciones prioritariasde la DNM se basaron en cuatrograndes problemáticas: 1) la actualización del dispositivo normativo de política migratoria, 2) la revisión de la estructura administrativa y territorial, 3) la apertura del organismo y 4) la regularización migratoria masiva. Retomando los componentes de la capacidad estatal propuestos por Bertranou (2013), estimamos que con respecto al punto 1) la DNM logró, luego de numerosos intentos, construir una sólida legitimidad para sostener su accionar y mantener su posición como autoridad migratoria, especialmente al momento de reglamentar la Ley 25.871. Este proceso constituyó uno de los mayores desafíos para demostrar su capacidad de adecuación al cambio institucional. Según un informe del CELS, la DNM tardó más de un año en presentar la propuesta de reglamentación por -entre otras razones- "las trabas y objeciones impuestas por funcionarios de la DNM que, por comodidad o posición ideológica, hacían lo imposible para que no se instrumentaran los cambios dispuestos por la nueva ley” (CELS, 2005). El primer borrador del proyecto remitido por la DNM contenía artículos enteros que pertenecían a la Ley Videla y que no 
se correspondían con la nueva normativa (Courtis y Pacecca, 2008). En medio de esta etapa de disputas por la reglamentación asumió la dirección Arias Duvalquien, por medio del Disposición DNM Nº 37.130 del año 2008 habilitó la formación de la Comisión Asesora del anteproyecto de reglamentación. Finalmente, la reglamentación llegó en el año 2010 y fue anunciada formalmente para los festejos del Bicentenario patrio.

Con respecto al punto 2), vinculado con la organización y los medios de acción en tanto componentes de la capacidad estatal de la DNM, se establecieron cambios en la estructura organizativa, en la dotación de personal, en el equipamiento de recursos y de tecnología del organismo y, paralelamente, se buscó lograr al interior del organismo el "cambio de cultura organizacional”. La profundización de los cambios en la organización comenzó a partir de la gestión de Arias Duval y tendieron a cubrir cuatro acciones primordiales de gestión: 1) la informatización mediante programas propios y específicos aplicando el expediente digital, accesible desde todas las Delegaciones para dar una "respuesta única” y no depender de la discrecionalidad de empleados o gestores; 2) la lucha contra la corrupción para “transparentar la administración” (modificaciones a la estructura organizativa), las reuniones "federales" de delegados y "posicionar al organismo” (DNM N4); 3) la formación de sus recursos humanos mediante cursos de capacitación, idiomas y atención y 4) la vinculación con otras instituciones del Estado y de la sociedad civil. Creemos importante remarcar, como indicamos en el Cuadro 1, que los nombres de algunas direcciones fueron cambiados para ser más acordes a la nueva normativa (la Dir. de Admisión de Extranjeros pasó a llamarse Dir. General de Inmigración mientras que la Dir. De Control Migratorio se rebautizó como Dir. Gral. De Movimiento Migratorio, por ejemplo). Cabría preguntarse si, pese a los cambios de terminología en sus responsabilidades primarias más acordes con la nueva gestión (“fiscalizar”, “dirigir”, "instrumentar”), las funciones de cada Dirección realmente cambiaron. Sobre la dotación de recursos, es evidente el aumento significativo de la planta de empleados totales, pasando de 653 en 1996 a 2084 en 2012 (Ver Cuadro 1) y llegando a 3800 en 2014, según la MIG de ese año.

Hasta ahora podemos afirmar que, desde el punto de vista de las capacidades del Estado para adecuarse a este cambio de política migratoria, la DNM tuvo la autorización legal-normativa necesaria para realizar las acciones que debía llevar a cabo, según el Art. 105 de la Ley 25.871. De hecho, no dejó de detentar su poder de policía sobre las cuestiones de control migratorio: pese a que la nueva normativa no tiene una orientación restrictiva, notamos en las acciones de la DNM un creciente aumento del control en la cantidad de inspecciones de admisión, los rechazos en frontera y la toma de 62 pasos fronterizos que antes estaban en manos de la Gendarmería Nacional Argentina en el año 2010 (Ver Cuadro 2). En cuanto a la legitimidad de sus acciones, la DNM intentó reforzarla por medio de la concertación con otros actores sociales, como vimos en el caso de la reglamentación y en la creación de la Mesa de Diálogo (Ver Cuadro 2). 
Los puntos 3) y 4) sobre la apertura del organismo y la regularización migratoria fueron de utilidad para examinar el capital de acción interorganizacional de la DNM en diferentes momentos. La apertura y la acción interorganizacional fueron un objetivo de la DNM y se establecieron algunas acciones en esa dirección. Sin embargo, la DNM no contó durante este período, exceptuando el caso de los foros internacionales migratorios (ONU, OIM, FEMM, etcétera), con mecanismos institucionalizados a priori de conexión con otras unidades del Estado. En el Capítulo III del Título X de la Ley 25.871, "De la relación entre Dirección Nacional de Migraciones con otros entes y organismos", se establece que, además del poder Judicial y los Registros Civiles, los Gobernadores provinciales y el Jefe de Gobierno de la Ciudad de Buenos Aires colaborarán con la DNM "en su carácter de agentes naturales del Gobierno Federal”, pero no se plantean acciones conjuntas institucionalizadas. Entre las acciones de las MIG figuran diferentes tipos de convenios, trabajos conjuntos y acuerdos con organismos estatales, sociales y académicos según sus campos de acción desarrollados entre los años 2003 y 2015. Gracias a las entrevistas realizadas notamos que estos vínculos tuvieron dos momentos: una primera etapa donde el objetivo fue posicionar a la DNM como absoluta autoridad en la cuestión migratoria. Para uno de los ex funcionarios de la DNM esto significaba tener el reconocimiento político para "ocupar los espacios” que le pertenecían al organismo:

"Si la Secretaría de Inteligencia del Estado se quería meter en un tema, nosotros decíamos que es un tema nuestro. Cuando la Policía se quería meter en un tema decíamos: no, este no es un tema de seguridad sino de migraciones (...) Nosotros lo hacíamos muy artesanalmente y nos poníamos la mochila al hombro” (DMN N 4).

En un segundo momento -y teniendo en cuenta este modo "artesanal" de relacionarse con otras instituciones- notamos que cada Departamento y Dirección dentro de la DNM se comienza a relacionar con otras unidades del Estado según sus afinidades temáticas y problemáticas. De esta manera, a nivel de la Dirección Nacional eran frecuentes las reuniones y coordinaciones con los servicios de seguridad (Fuerzas de Seguridad y servicios secretos) o con los CAJ (Centros de Acceso a la Justicia) ${ }^{8}$, a nivel de la Dirección de Asuntos Internacionales y Sociales las reuniones se realizaban en conjunto con la Cancillería (DNM Nº 5) y así según cada área.

Además, consideramos que fue la necesidad de regularizar masivamente a migrantes indocumentados la que mostró las limitaciones de la acción interorganizacional de la DNM. Como explica un entrevistado, en la DMN“salieron como pudieron a aplicar el Programa Patria Grande, que se empezó a implementar entre el 2005 y 2006, era la emergencia!” (DNM Nº 4).

El Programa se instrumentó a partir de la Disposición DNM N 53.253/ 2005 y, mientras en Sede Central se trabajaba con turnos desde las 7 AM hasta las 22 PM, en el interior del país se evidenció la incapacidad de llegar a la regularización por fallas organizacionales de estructura así como por la ausencia de redes interorganizacionales. La entrevistada DNM $\mathrm{N}^{\circ} 1$ relata que: 
“(...) se lanza este programa patria grande y la idea es llegar a todos los inmigrantes, que el Estado vaya (...) una de las cláusulas es firmar convenios con los distintos municipios, en ese marco surge que en algunas provincias no había ni delegación de la DNM” (DNM N 1).

Desde el punto de vista de las capacidades estatales fue menester, entonces, salir primero del estado de emergencia y actualizar la estructura general y territorial de la DNM. A partir de estas acciones descriptas podemos concluir que la mayoría de los cambios exitosos dentro de la DNM estuvieron enfocados en aumentar la eficiencia del organismo, al punto de ser distinguida por el Instituto Nacional de la Administración Pública (INAP) en el año 2015. Este interés de modernizar a la DNM está más vinculado, sin embargo, a los requerimientos de la gestión pública que a la adecuación a la "nueva orientación” de la normativa.

Pero también, al interior del organismo hacía falta un “cambio de cultura organizacional” que acompañara estas acciones. Como observaremos en el último apartado, los cambios en la cultura organizacional implicaban que los funcionarios de la DNM no sólo fueran modificando los protocolos de atención sino también las actitudes y las formas de pensar/se “desde el Estado” que se correspondían con la legislación anterior.

\section{El Estado a través de sus agentes o “desde adentro”}

Hasta aquí examinamos las acciones que llevó a cabo la DNM para cumplir con sus objetivos y notamos una creciente autonomía relativa y capacidad del organismo para posicionarse como actor destacado de la política migratoria argentina adecuándose a la nueva normativa. Sin embargo, estimamos que uno de los objetivos encontró más resistencias al interior del organismo: el del "cambio de cultura organizacional”. La "cultura” de los trabajadores de la DNM debía comenzar a incorporar el respeto a los DDHH de los migrantes y comprender su lugar de atención y servicio como agentes estatales para tratar de manera respetuosa a aquellos que se acerquen a la institución. Para ello, se llevaron a cabo algunas acciones como el establecimiento de mayores vínculos con migrantes, con organismos de DDHH y académicos, cursos para la atención pública de los empleados, etcétera. Ahora bien: ¿qué “cultura” prevalecía en la DNM antes del año 2004? Para comprender de qué se trataba el cambio, retomamos las palabras de un ex funcionario DNM:

“(...) la cultura organizacional de la DNM era como un híbrido, un organismo muy cerrado, todo adentro, nada hacia afuera, y no tenían muy claro, los de la DNM, si eran empleados administrativos del estado o eran una organización cuasi policial. No lo tenían muy claro, de hecho creo que estaban más por la opción b) que por la a), sobre todo los inspectores” (DNM N4). 
Las resistencias al cambio normativo y de cultura organizacional las encontramosen el trabajo de aquellos empleados que debían "tratar" con los migrantes. Un ex funcionario nos relataba:

“[la resistencia a la nueva ley] era muy difícil de ser controlada en el trato habitual del extranjero, había que ejercer una permanente vigilancia para que se aplique la norma, sobre todo cuando ésta no estaba aún reglamentada y había muchas disposiciones que contradecían específicamente el espíritu de la ley” (DNM N² 2).

Por otro lado, gracias a las entrevistas comprendimos las tensiones al interior del organismo con respecto a la nueva normativa y el trato a los migrantes, porque otros empleados creían que, pese al aumento de los controles fronterizos y de permanencia, los rechazos en frontera y las expulsionesrealizadas gracias a los avances tecnológicos, la DNM estaba perdiendo su poder de policía y de control, como es el caso de DNM $\mathrm{N}^{\circ} 3$, un empleado conmuchos años de antigüedad que expresa:

“(...) prácticamente la normativa nueva permitía que casi cualquier persona pudiera radicarse, ya no existió más el “inhábil absoluto” y el "inhábil relativo". (...) Se pasó del alfa al omega. Vos podés decir: ¿lo anterior era bueno? Para mí lo anterior era bueno, tenías posibilidades, no era que no se podía radicar la persona. Estaba más limitadito [el migrante] porque el mismo Estado ejercía su poder de control. Hubo un momento, con el gobierno anterior (Néstor Kirchner o Cristina Fernández de Kirchner), que se descontroló todo” (DMN $\mathrm{N}^{\circ}$ 3, resaltado de la autora).

Observamos así que detrás de las normas, las disposiciones y los informes hay personas que intervienen cotidianamente en la sociedad en nombre del Estado y que se disputan poder en su interior. Como explica Abrams (1977) el Estado tiene la capacidad de presentarnos “(...) el poder políticamente institucionalizado de una forma que es a la vez integrada y aislada y al satisfacer ambas condiciones crea para nuestra clase de sociedad una base aceptable de acuerdo" (Abrams, 1977, p. 88). De nuestros cinco entrevistados, tres de ellos tuvieron un cargo de alto funcionario de la DNM en distintas partes del país y, dada esa posición, en su relato articulaban directamente su identificación con la función pública. Para uno de ellos la unión entre el organismo y las personas que lo componen era directa: como la DNM no tenía una identidad definida, sus empleados tampoco la tendrían. Según su punto de vista era necesario que los funcionarios tuvieran "una visión más global de lo que significa un organismo del Estado, de en qué medida ellos están aportando a la política migratoria de un país o como se puede sostener o modificar una política migratoria desde la gestión” (DMN N 4).

Para algunos empleados la “cuestión” política de las migraciones era el objetivo fundamental de su labor, como expresa DNM N 5: “(...) para mí 
la cuestión migratoria era el medio y el fin, pero no para todos los que trabajaban ahí era lo mismo" (DNM N 5).

Descubrir estas diferentes visiones sobre el "trabajar en/para el Estado", así como desentrañar la manera "artesanal” en que se tejen algunas relaciones institucionales,nos recuerda entonces que, pese a la extensa burocratización estatal, el Estado opera a partir de las personas que lo conforman, que tienen poder de agencia y que en virtud de ese podertoman decisiones según sus recursos, capacidades e ideologías. A través de los agentes entrevistados pudimos encontrar tensionesentre la visión de servicio administrativo y la visión policial que supone el "cambio de cultura organizacional” así como entrever una tensión entre la adecuación a la nueva normativa y los costos políticos de las decisiones administrativas que deberían tomarse. Como explica una ex funcionaria de Rosario:

“(...) hubo nuevos organismos, hubo más cooperación interinstitucional con universidades, había publicaciones... una apertura del organismo y algunas resistencias (...) Sí, se pudo gestionar al interior del Estado con la ley de tu lado y un gran margen de autonomía política relativa. Se puede... pero con un gran costo político" (DNM N³).

Si retomáramos la idea de la forma en que se piensa el Estado a través de sus agentes y acciones deberíamos entonces tener en cuenta los intentos de modernización de la gestión pública, la preocupación por la adecuación a la nueva normativa y el mantenimiento de los dispositivos de control y regulación de migrantes y fronteras como parte indispensable de la función de la DNM.

\section{Conclusiones: Objetivos, acciones y capacidades}

En este artículo nos propusimosindicar, desde una perspectiva institucionalista y centrada en los aportes de la sociología y la ciencia política, las acciones desarrolladas por la DNM para adecuarse a la Ley 25.871 a partir del año 2004. Tomamos un momento de cambio del dispositivo normativo de política pública para examinar, en un punto de inflexión concreto, los recursos y medios con los que contó la unidad del Estado que detenta la autoridad de aplicación de la Ley para, en términos de Oszlak y O’Donnell (2007 [1978]), redefinir la cuestión migratoria y lograr que se cristalice a nivel institucional.

Observamos que el cambio normativo de política pública supuso ciertas transformaciones previas que la habilitaron. Entre estas transformaciones, dos son las más relevantes: la inclusión de actores con intereses diversos en la discusión de la cuestión migratoria y los aspectos formales de la normativa, es decir, el debate en ambas Cámaras legislativas y la posterior sanción. Aunque la nueva Ley supuso para el Estado un cambio de orientación por respetar los DDHH y por aplicar el criterio regionalista, la 
misión y función del dispositivo de gestión DNM no conllevó grandes modificaciones. Sin embargo, el organismo debía llevar a cabo numerosas acciones para poder dar cuenta de las consecuencias inmediatas de la nueva normativa.

Y son estas acciones las que nos indican las aptitudes para cumplir con los fines requeridos de la DNM, es decir, su capacidad Estatal. En términos de Enríquez y Centeno (2012), nuestra noción de capacidad estatal se vincula a la noción de autonomía del Estado (con respecto a los poderes internos como internacionales) para llevar adelante sus preferencias políticas, tomar decisiones, implementarlas y contar con competencias técnicas para mantenerlas y hacerlas cumplir. En este caso, encontramos una relación entre las capacidades y los objetivos que se impone el mismo organismo del Estado en cada cuestión particular.Para cada objetivo, deben darse determinadas acciones, que fueron las que evaluamos en esta oportunidad ${ }^{9}$.

En este primer acercamiento a la institución, observamos que contó con la autorización legal ("la Ley de tu lado") y la legitimidad para cumplir con sus funciones $\mathrm{y}$, sobre todo, para realizar las acciones necesarias al interior del organismo. El Decreto del PEN que la declaró en emergencia administrativa fijó los lineamientos generales de las acciones que debían ser inmediatas: la re-estructuración del organismo, optimizar la dotación de recursos humanos (contratación, capacitación y redistribución) y aplicar un programa masivo de regularización documentaria para inmigrantes irregulares. Al cumplir con este estado de emergencia, la DNM mejoró sus aptitudes en lo que respecta a otro componente de la capacidad estatal: la organización y los medios de acción. Se abrieron delegaciones, oficinas, se retomaron 62 pasos fronterizos y se lanzó el Programa de Abordaje Territorial para tener mayor control y cubrir las necesidades de todo el país. Se reestructuró el organismo, se crearon Direcciones y Departamentos, se modificó la estructura edilicia y se implementaron sistemas informáticos propios específicos para cada área. También descubrimos una capacidad "artesanal” de acción interorganizacional, llevada a cabo por cada área de la DNM con otros entes estatales y no estatales según sus intereses y competencias, evidenciando la capacidad e interés de los agentes de la DNM en ese tipo de gestión estatal. Hasta aquí descubrimos que los mayores avances en el publicitado cambio de orientación del Estado y de la DNM con respecto a la cuestión migratoria se dieron justamente en el ámbito institucional u organizacional, o sea, en mejorar la capacidad estatal. La gestión de la DNM mostró cada vez más acciones tendientes a normalizar, transparentar y aumentar su eficiencia, siguiendo los requerimientos modernizadores de la gestión pública, aunque esto no estuviera necesariamente ligado a la "nueva orientación" de la normativa.Paralelamente, se generaron acciones para cambiar "la cultura organizacional” mejorando los vínculos de la DNM con organismos de DDHH y de migrantes, por ejemplo.

Con respecto a esto último y para finalizar, nos interesa destacar dosresultados de nuestra indagación que ameritan una mayor profundización analítica. En primer lugar, estimamos que las acciones tendientes a generar 
un cambio cultural organizacional son las que encontraron mayores resistencias al interior de la DNM. Comprobar la causa de esas resistencias implicaría indagaren los resultados de esas acciones en un largo plazo. Sería menester, en investigaciones futuras, averiguar cuáles de las acciones generaron mayor resistencia, si las directas y obligatorias como los cursos de idiomas, por ejemplo, o las indirectas u orientativas como los eventos sociales realizados con los migrantes. Además, se impone la realización de una mayor cantidad de entrevistas para identificar dichas resistencias con posibles perfiles de agentes estatales según su cargo, edad, género, antigüedad en la DNM, formación, etcétera. En ese sentido y en segundo lugar notamos que, vis a vis la defensa del discurso de la migración como un DDHH y de la inclusión del migrante en la sociedad, entre las acciones destinadas a adecuarse a la nueva normativa, encontramos numerosas consignadas exclusivamente a aumentar, mejorar y profundizar la seguridad en los controles, ya sea fronterizos o de permanencia. El aumento y perfeccionamiento de sus medios de acción en estas funciones de control y regulación (inspección, expulsión, rechazo en frontera, registro), aunque no implica contradicciones con la normativa nacional nos lleva a pensar que la DNM, a partir de su propia capacidad y por medio de sus disposiciones y resoluciones -y tal vez de sus propias decisiones políticas-, cuenta aún con una autonomía relativa que le permite bascular cómodamente y voluntariamente todavía en el debate sobre su propia identidad, oscilando entre ser un organismo administrativo o una fuerza policial. 


\section{Notas}

${ }^{1}$ Ver Sassone (2004), Courtis (2006), Novick (2008, 2012), Le Gall y Sassone (2008), Nejamkis (2012), Penchaszadeh (2012), CELS (2005), entre otros.

${ }^{2}$ Las primeras entrevistas se realizaron en la Delegación La Pampa en los años 2014 y 2015 en el marco de un Proyecto de Investigación Orientada (PIO CONICET/ UNLPam) (Resolución N 4213/ 02-11-2015) denominado “Desarrollo, región y capacidades estatales: un estudio de instituciones, empresas y políticas públicas en el largo plazo". Mediante la técnica de "bola de nieve" se establecieron luego los contactos con otros empleados y ex empleados para realizar las entrevistas en Rosario y Buenos Aires en el año 2016.

${ }^{3}$ A continuación de las referencias al final del artículo, se colocan los perfiles de los entrevistados según lugar de delegación, tipo de cargo, antigüedad, año en que fue realizada la entrevista y si continúa o no en el cargo.

${ }^{4}$ Susana Novick realiza un recorrido conceptual por la noción de "política de población” y acaba por tomar el concepto de Miró (1998, citado por Novick 2001), quien establece que la política de población determina metas relativas a los valores deseables en cuanto a a) la magnitud de la población total de un país, b) la tasa anual de crecimiento de la población y c) la modificación de las tendencias de la migración internacional o interna.

${ }^{5}$ Esta línea de análisis, más cercana a la perspectiva de la Antropología del Estado, es trabajada con mayor rigor y profundidad en el marco del Proyecto PIO CONICET/ UNLPam antes mencionado. En esta oportunidad, teniendo en cuenta el objetivo de este artículo y las limitaciones formales del mismo, nos valdremos de las entrevistas solamente para ejemplificar las tensiones y diferentes perspectivas presentes en los agentes estatales de un mismo organismo.

${ }^{6}$ Esta ley, como otras leyes restrictivas (Anguiano y López Sala, 2010), no desalentó la migración (los migrantes seguían llegando a Argentina) sino que, una vez en el país, condenó a los recién llegados a situaciones de vulnerabilidad social a causa de la explotación laboral, la pobreza, el hacinamiento, los problemas de salud, el analfabetismo, etcétera (Рacecca, 2000).

${ }^{7}$ Informe de Control Interno y Gestión (ICIG) del período 2003-2007.

${ }^{8}$ Los Centros de Acceso a la Justicia tienen alcance federal y son dispositivos para brindar respuestas a problemas socio-legales de la comunidad.

${ }^{9}$ Planteado de esta manera, entendemos que la capacidad de un ente estatal no necesariamente se debe evaluar en términos de los resultados de sus políticas públicas. Si así fuera, deberíamos haber focalizado nuestro análisis en un abordaje más cuantitativo así como cualitativo- sobre los alcances de las acciones de la DNM y de su recepción en los grupos con quienes este organismo trabaja (aumento de la cantidad de radicaciones/ permisos de residencia, o la operacionalización de los trámites desde la óptica de los propios migrantes, por ejemplo). 


\section{Bibliografía}

Abrams, P. (1988 [1977]). Notas sobre la dificultad de estudiar el estado.Journal of HistoricalSociology, (1), 58-89.

Acuña, C., yChudnovsky, M. (2013). Cómo entender las instituciones y su relación con la política: lo bueno, lo malo y lo feo de las instituciones y los institucionalismos.En C. Acuña (comp.), ¿Cuánto importan las instituciones? Gobierno, estado y actores en la política argentina.(pp. 19-67).Buenos Aires, Argentina: Siglo Veintiuno Editores.

Anguiano, M. E., y López Sala, A. M. (Eds.) (2010).Migraciones y fronteras. Nuevos contornos para la movilidad internacional. Barcelona, España: CidobEdicions.

Badaró, M. (2006). La conciencia y la ley: la cuestión migratoria en la práctica de las agencias estatales y organismos no gubernamentales en la ciudad de Buenos Aires. En A. Grimson y E. Jelin (comps.),Migraciones regionales hacia la Argentina. Diferencia, desigualdad y derechos. (pp. 207- 235). Buenos Aires, Argentina:Prometeo.

Bertranou. J. (2013). Creación de agencias especializadas, capacidad estatal y coordinación interinstitucional. Análisis del caso de la Agencia Nacional de Seguridad Vial en Argentina.Perspectivas de políticas públicas, 2 (4), 11-39. DOI: http://dx.doi.org/10.18294/ rppp. 2013.621

Bohoslavsky, E., y Soprano, G. (Eds.). (2010).Un estado con rostro humano: funcionarios e instituciones estatales en Argentina de 1880 hasta la actualidad. Buenos Aires, Argentina:Prometeo.

CELS (Centro de Estudios Legales y Sociales). (1999). Inmigración, política estatal y vigencia de los Derechos Económicos, Sociales y Culturales de los inmigrantes y trabajadores migratorios peruanos y bolivianos en Argentina. Informe realizado para la Plataforma Sudamericana de Derechos Humanos, Democracia y Desarrollo, Buenos Aires, 1999.

CELS (Centro de Estudios Legales y Sociales). (2005).Informe Anual sobre la Situación de los Derechos Humanos en Argentina, Capítulo XIV: A dos años de la nueva Ley de Migraciones: avances, cuestiones pendientes y casos preocupantes, Buenos Aires, Argentina: CELS

CELS-FIDH. (2011).Argentina. Avances y asignaturas pendientes en la consolidación de una política migratoria basada en los derechos humanos. Paris, Francia: Federación Internacional de Derechos Humanos. 
Courtis, C. (2006). Hacia la derogación de la Ley Videla: la migración como tema de labor parlamentaria en la Argentina de la década de 1990. En A. Grimson y E. Jelin (comps.), Migraciones regionales hacia la Argentina. Diferencia, desigualdad y derechos. (pp. 169-205). Buenos Aires, Argentina: Prometeo.

Courtis, C., y Pacecca, M. (2008).Inmigración contemporánea en Argentina: dinámicas y políticas. Centro Latinoamericano y caribeños de demografía (CELADE)- División de Población de la CEPAL, Santiago, Chile: CEPAL.

Domenech, E. (2009).La visión estatal sobre las migraciones en la argentina reciente. De la retórica de la exclusión a la retórica de la inclusión. En E. Domenech (comp.),Migración y política: el Estado interrogado. Procesos actuales en Argentina y Sudamérica.(pp. 21-70). Córdoba, Argentina: UNC., recuperado de https://www.aacademica.org/ eduardo.domenech/34.pdf

Domenech, E. (2013).Las migraciones son como el agua: Hacia la instauración de políticas de “control con rostro humano"Polis, Revista Latinoamericana12 (35) 119-142.DOI: http://dx.doi.org/10.4067/S071865682013000200006 .

Enriquez, E., y M. A. Centeno. (2012).State capacity: Utilization, Durability, and the Role of Wealth vs. History.International and Multidisciplinary Journal of Social Sciences, (2),130-162. DOI: http://dx.doi.org/ 10.4471/rimcis.2012.07

Espinoza, E. (2015). Notas sobre la dificultad de etnografiar el Estado.Estudios Sociales del Estado,(2), 175-186. Recuperado de: http://estudiossocialesdelestado.org/index.php/ese/article/view/40

Evans, P. (2007).Instituciones y desarrollo en la era de la globalización neoliberal. Bogotá, Colombia:Ilsa.

Isuani, F. (2012). Las capacidades estatales. En C. Alza Barco (Ed.), Actas del VI Seminario de Reforma del Estado: Gestión pública: balance y perspectivas. (pp. 25-43). Lima, Perú: Fondo Editorial de la Pontificia Universidad Católica del Perú.

Le Gall, J., y Sassone, S.M. (2008).Tournant des politiquesmigratoires en Argentine.EchoGéo, (3)DOI: 10.4000/echogeo.1850.

Nejamkis, L. (2016).Políticas migratorias en la Argentina 1976-2010. De la "Doctrina de Seguridad Nacional” a la consolidación del Derecho Humano a la migración. Buenos Aires, Argentina: Prometeo.

Nejamkis, L. (2012). Políticas migratorias en tiempos Kirchneristas (20032010): ¿un cambio de paradigma? En S. Novick (dir.), Migraciones y 
Políticas Públicas, Nuevos escenarios y desafíos.(pp. 89 - 116). Buenos Aires, Argentina: Catálogos.

Novick, S. (2001).Democracia y población: Argentina 1983-1999. Documentos de Trabajo $\mathrm{N}^{\circ}$ 28. Buenos Aires, Argentina: Ed. Instituto de Investigaciones Gino Germani, Facultad de Ciencias Sociales, Universidad de Buenos Aires. Recuperado de: http:// biblioteca.clacso.edu.ar/Argentina/iigg-uba/20100408015507/dt28.pdf

Novick, S. (2008). Migración y políticas en Argentina: tres leyes para un país extenso (1876-2004). En S. Novick(comp.),Las migraciones en América Latina. Políticas, culturas y estrategias. (pp. 131-151). Buenos Aires, Argentina: Catálogos.

Novick, S. (2012). Introducción. En S. Novick (dir.), Migraciones y Políticas Públicas, Nuevos escenarios y desafíos. (pp. 13-38). Buenos Aires, Argentina: Catálogos.

O’Donnell, G.,y L. Wolfson(1993). Acerca del Estado, la Democratización y Algunos Problemas Conceptuales. Una perspectiva latinoamericana con referencias a países poscomunistas.Desarrollo Económico,(XXXIII), (130) 63-184. DOI: 10.2307/3467251

Oszlak, O., y O’Donnell. G. (2007 [1978]).Estado y políticas estatales en América latina: hacia una estrategia de investigación. En C. Acuña (comp.),Lecturas sobre el Estado y las políticas públicas: Retomando el debate de ayer para fortalecer el actual, en Proyecto de Modernización del Estado, Jefatura de Gabinete de Ministros, Estudios CEDES, 1 (3), 1978: Buenos Aires.

Pacecca, M. I. (2000).Legislación, migración limítrofe y vulnerabilidad social.Realidad Económica No 171, Instituto Argentino para el Desarrollo Económico (IADE).

Penchaszadeh, A. P. (2012). Migraciones y derechos políticos: ¿Democratización y extensión de la ciudadanía o nuevas formas de la extranjerización en democracia?En S. Novick (dir.), Migraciones y Políticas Públicas, Nuevos escenarios y desafíos.(pp. 39-62). Buenos Aires, Argentina: Catálogos.

Renoldi, B. (2015). Estados posibles: travesías, ilegalismos y controles en la Triple frontera.Etnográfica, 3 (19) 417-440. DOI: 10.4000/ etnografica.4049

Sassone, S. M. (2004). Políticas migratorias y la integración en el Mercosur: Actores institucionales y tensiones emergentes en la República Argentina.Geodemos, (7/8) 179-220. 
Skocpol, T. (1995). El Estado regresa al primer plano: Estrategias de análisis en la investigación actual.En R. Grompone (Ed.), A. Adrianzén, J. Cotler y S. López (comps.),Instituciones políticas y sociedad. Lecturas introductorias. (pp.92-129). Lima, Perú: IEP.

\section{Entrevistas:}

DNM No 1: Empleado, alto funcionario, 16 años antigüedad, Delegación La Pampa. Santa Rosa, año 2014 y 2015. Continúa empleado.

DNM N²: Empleado, alto funcionario, 10 años antigüedad Delegación Rosario. Rosario, Marzo 2016. No continúa empleado.

DNM N 3: Empleado, 38 años de antigüedad, Delegación Sede central. Buenos Aires, octubre 2016. Continúa empleado.

$\mathrm{DNM}^{\circ}$ 4: Alto funcionario, 8 años de antigüedad, Delegación Sede Central. Buenos Aires, octubre 2016. No continúa en el cargo.

DNM N ${ }^{\circ}$ 5: Empleado, 3 años de antigüedad, Delegación Sede central. Buenos Aires, octubre 2016. No continúa empleado.

\section{Normativa consultada y citada:}

República Argentina, DNM, Memorias Institucionales de Gestión (MIG). Años 2008, 2009, 2010, 2011, 2012, 2013, 2014 y 2015.

República Argentina, DNM, Informe de Control Interno y Gestión (ICIG). Período 2003-2007.

República Argentina, Decreto 4418/1965, Reglamento de Migración, Buenos Aires, 4 de junio de 1965.

República Argentina, LEY N²2.439/1981. Ley general de migraciones y de fomento de la inmigración, publicada en el Boletín Oficial el 27 de marzo de 1981.

República Argentina, DECRETO 1659/96 del P.E.N..Apruébase la estructura organizativa del citado organismo descentralizado, Bs. As., 27/ 12/96. Publicado en el Boletín oficial el 15 de Enero de 1997.

República Argentina, LEY 25.871/2004, Ley de migraciones, Política migratoria argentina, publicada en el Boletín Oficial el 21 de enero de 2004.

República Argentina, DECRETO 836/2004, DIRECCION NACIONAL DE MIGRACIONES, Declárase la emergencia administrativa del ci- 
tado organismo descentralizado de la órbita del Ministerio del Interior, publicada en el Boletín Oficial el 7 de julio de 2004.

República Argentina, DECISIÓN ADMINISTRATIVA 250/2008, JEFATURA DE GABINETE DE MINISTROS, Dirección Nacional de Migraciones, Estructura organizativa - Aprobación, Buenos Aires, 25 de junio de 2008. Publicada en el Boletín Oficial el 30 de junio de 2008.

República Argentina, DECRETO 616/2010 P.E.N., Migraciones, Reglamentación de la Ley de Migraciones $\mathrm{N}^{\mathrm{0}} 25.871$ y sus modificatorias, Buenos Aires, 3 de mayo de 2010.

República Argentina, DECISIÓN ADMINISTRATIVA 1395/2012. JEFATURA DE GABINETE DE MINISTROS, Dirección Nacional de Migraciones, Estructura organizativa - Aprobación, Buenos Aires, 20 de diciembre de 2012. Publicada en el Boletín Oficial de 27 de diciembre de 2012

Recibido: 07.04.17

Aceptado: 20.09.17 